SCIENTIFIC LETTER

\title{
Carer knowledge of children's medical problems in a paediatric cardiology outpatient setting
}

\author{
J Wray, G Small, B Freedman, R C G Franklin
}

Heart 2004;90:213-214. doi: 10.1136/hrt.2003.004895

1 a world with increasingly mobile populations, children often attend emergency departments or primary care surgeries where no documentation about existing medical problems is held. This can cause difficulties, especially for children with chronic and ongoing medical conditions. Advances in medical and surgical care have resulted in dramatic improvements in mortality and morbidity rates and a steady and continuing increase in this population. This is especially true for children with congenital heart disease in whom there is a significant population with repaired or palliated lesions. Such children are at risk of suboptimal treatment when they present for emergency care from unfamiliar health care providers. ${ }^{1}$ Health care professionals are reliant on parents or caregivers to give relevant histories and contact information, so becoming the child's principal advocate in accessing optimal health care.

Information about parental understanding of congenital heart disease is scant, but a lack of knowledge about bacterial endocarditis and antibiotic prophylaxis has been identified in parents of these children. ${ }^{2}$ The aim of this study was to assess the ability of parents attending a tertiary paediatric cardiology centre to give accurate information concerning their child's medical condition, including the need for antibiotic prophylaxis for dental procedures.

\section{METHODS}

Caregivers who attended an outpatient clinic with their child in a tertiary paediatric cardiology centre (November 1998 to January 1999) were approached for consent and interviewed before they were seen by the clinician for their appointments. Once they had consented to the study, the caregivers were seen by one of two interviewers (GS, BF). Each question was read verbatim to ensure consistency in the approach of the interviewer to obtaining information. The answers were recorded by writing down the words spoken. Ethical approval was obtained for the study.

Parents and carers of children who attended outpatient clinics for follow up of their cardiac condition, spoke English, and were able to give consent to the study were included. Patients were excluded if they had received an organ transplant, did not have a consistent carer, were attending the clinic as new patients, or were known to either of the interviewers.

Parents were asked questions aimed at establishing their ability to explain their child's diagnosis to a medical professional. The questions were devised specifically for this study and focused on parents' knowledge about their child's diagnosis and antibiotic prophylaxis for dental and other treatment.

Following the interview both interviewers reviewed the case notes to determine the accuracy of the information received. The ability of each caregiver to give accurate medical information was rated according to a scoring system devised specifically for this study (table 1 ).

\section{RESULTS}

All 85 families approached agreed to participate. All carers were parents of the study children. Mean age of the children was 4.9 (range $0.2-12.9$ ) years, 54 (64\%) were male, and 42 (49\%) had undergone previous cardiac surgery.

Results concerning knowledge of diagnosis are shown in table 2 . For $26 \%$ of children, parents were unable to give an explanation which would have allowed a health professional unfamiliar with the medical history to understand the diagnosis. Mothers scored better than fathers. There were no correlations between understanding of diagnosis and previous surgery, the morphological diagnosis, the child currently taking cardiac related medication $(\mathrm{n}=13,15 \%)$ or the previous provision of diagnosis related written information $(\mathrm{n}=30,35 \%)$.

In response to whether or not carers thought their child needed any special treatment on visiting the dentist, 62 (73\%) gave the correct response. Those that required antibiotic prophylaxis knew that it was required for treatments and not for simple check ups.

\section{DISCUSSION}

Children with special health care needs are an increasing population. Like healthy children, those with underlying chronic health problems will present requiring emergency treatment to health care providers unfamiliar with their medical history. Almost a quarter of children presenting to an urban paediatric emergency department have one or more chronic medical conditions. ${ }^{3}$ If such children are to receive optimal care it is essential that accurate, up to date information is available to health care providers. It is the child's carer who will be asked to provide such details.

Within this study, children were being followed up in a tertiary paediatric cardiology centre with no emergency facility. If acutely unwell, these children would present elsewhere. Of the carers in this study, 22 (26\%) could not have given a description of their child's condition which would have allowed a health professional unfamiliar with their specific medical history to understand the diagnosis. Implicitly, the child might receive inappropriate treatment,

Table 1 Scoring criteria for carer knowledge of diagnosis

Score Criteria for using score

1 Carer gave correct medical terminology to explain their child's condition

2 Carer used layman's terms to describe their child's condition. The layman's terms given allowed the correct medical diagnosis to be deciphered

3 Carer used layman's terms which suggested a probable medical diagnosis but left the exact diagnosis unclear.

4 Carer aware of the vague nature of the child's condition 5 Carer had no idea of the diagnosis 
Table 2 Ratings of knowledge about diagnosis and need for antibiotic prophylaxis

\begin{tabular}{|c|c|c|c|c|c|c|c|}
\hline & \multicolumn{5}{|c|}{ Rating of carer knowledge of diagnosis ( $n=85$ ) } & \multicolumn{2}{|c|}{$\begin{array}{l}\text { Correct knowledge about } \\
\text { need for antibiotic } \\
\text { prophylaxis }(n=85)\end{array}$} \\
\hline & 1 & 2 & 3 & 4 & 5 & Yes & No \\
\hline Mother & 27 & $\overline{9}$ & 6 & 3 & 0 & 34 & 11 \\
\hline Father & 4 & 4 & 0 & 2 & 1 & 5 & 6 \\
\hline Both & 13 & 6 & 4 & 5 & 1 & 23 & 6 \\
\hline Total & $44(52 \%)$ & $19(22 \%)$ & $10(12 \%)$ & $10(12 \%)$ & $2(2 \%)$ & $62(73 \%)$ & $23(27 \%)$ \\
\hline
\end{tabular}

particularly in situations where time sensitive decisions need to be made. Similar findings were reported for children with a wide range of chronic conditions, where $30 \%$ of carers were unable to provide a meaningful explanation of the child's diagnosis to non-specialist health care providers. ${ }^{4}$

Furthermore, 23 carers $(27 \%)$ gave an incorrect response regarding their child's need for antibiotic prophylaxis for dental or surgical treatment, supporting previous research identifying a lack of knowledge about endocarditis and antibiotic prophylaxis in parents of children with congenital heart disease. ${ }^{2}$ By current guidelines, 18 of these 23 patients would have needed such prophylaxis, while five patients had carers who felt they needed antibiotic prophylaxis, when it was in fact unnecessary.

This is a relatively small study, covering children with a wide range of cardiac diagnoses. Only carers attending clinic were interviewed, which may have resulted in a sample bias as these parents were more adherent with their child's care, and perhaps more knowledgeable. The data from this study and of other groups of chronically ill children indicate a need for a mechanism by which health care providers unfamiliar with a child's medical history can have access to such information. Currently, there is a move towards patient held records. It has been suggested that "smart" cards will play a pivotal role in future health care, ${ }^{5}$ but only if patients and their families adhere to the demands of such a system by carrying the cards with them. At present, it is crucial that basic informational needs are addressed, so enhancing parental knowledge about their child's diagnosis and medication(s), as well as the child's or adolescent's own knowledge to cater for situations where carers are not available. Efforts to provide accurate, individualised information for parents and children need to be intensified and the efficacy of different mechanisms for delivering such information audited. Enhanced understanding of the illness and its treatment has implications not only for the physical wellbeing of these patients but also for their psychological welfare, quality of life, and their adherence to the prescribed treatment protocols.

\section{Authors' affiliations}

J Wray, G Small, B Freedman, R C G Franklin, Royal Brompton and Harefield NHS Trust, Harefield Hospital, Harefield, Middlesex, UK

Correspondence to: Dr J Wray, Paediatric Surgical Unit, Royal Brompton and Harefield NHS Trust, Harefield Hospital, Harefield, Middlesex, UB9 6JH, UK; j.wray@rbh.nthames.nhs.uk

Accepted 9 June 2003

\section{REFERENCES}

1 Saccheti A, Sacchetti C, Carraccio C, et al. The potential for errors in children with special health care needs. Acad Emerg Med 2000;7:1330-3.

2 Cetta F, Bell TJ, Podlecki DD, et al. Parental knowledge of bacterial endocarditis prophylaxis. Pediatr Cardiol 1993;14:220-2.

3 Reynolds S, Desquin B, Uyeda A, et al. Children with chronic conditions in a pediatric emergency department. Pediatr Emerg Care 1996;12:166-8.
4 Caraccio CL, Dettmer KS, duPont ML, et al. Family member knowledge of children's medical problems: the need for universal application of an emergency data set. Pediatrics 1998;102:367-70.

5 Neame R. Smart cards-the key to trustworthy health information systems. BM 1997; 314:573-7

\section{WEB TOP 10}

www.heartinl.com

These articles scored the most hits on Heart's website during November 2003

1 Role of myocardial perfusion imaging for risk stratification in suspected or known coronary artery disease NK Sabharwal, A Lahiri

November 2003;89:1291-7. (Review)

2 The role of echocardiography in atrial fibrillation and cardioversion

RW Troughton, CR Asher, AL Klein

December 2003;89:1447-54. (Education in Heart)

3 The human coronary collateral circulation

C Seiler

November 2003;89:1352-7. (Education in Heart)

4 Diastolic heart failure: fact or fiction?

JE Sanderson

November 2003;89:1281-2. (Editorial)

5 Drug induced QT prolongation and torsades de pointes YG Yap, AJ Camm

November 2003;89:1363-72. (Education in Heart)

6 Athlete's heart

$R$ Fagard

December 2003;89:1455-61. (Education in Heart)

$7 \mathrm{C}$ reactive protein for risk stratification in acute coronary syndromes? Verdict: unproven

$S$ Kennon, AD Timmis, $R$ Whitbourn, $C$ Knight

November 2003;89:1288-90. (Viewpoint)

8 Are troponins confusing?

PO Collinson, PJ Stubbs

November 2003;89:1285-7. (Editorial)

9 Circulating concentrations of cardiac proteins indicate the severity of congestive heart failure

T Goto, H Takase, T Toriyama, T Sugiura, K Sato, R Ueda, Y Dohi

November 2003;89:1303-7. (Cardiovascular medicine)

10 Thrombolysis: newer thrombolytic agents and their role in clinical medicine

TK Nordt, C Bode

November 2003;89:1358-62. (Education in Heart)

Visit the Heart website for hyperlinks to these articles, by clicking on "Top 10 papers"

www.heartinl.com 